\title{
Electro-capacitive performance of haemoglobin/polypyrrole composites for high power density electrode
}

\author{
Komal Khati, Ila Joshi and Mohammad Ghulam Haider Zaidi
}

\begin{abstract}
Background: Haemoglobin (Hb)-doped polypyrrole (PPy) composites serving as energy storage material have rarely been premeditated.

Methods: In this perspective, a novel class of haemoglobin/polypyrrole composites (HPyCs) by doping metal derivative $\mathrm{Hb}$ into PPy matrix with concentrations (PPy, 1\%, 2\% and 3\% $\mathrm{Hb}$ in $\mathrm{w} / \mathrm{W}$ ) has been synthesized by cationic surfactant assisted dilute polymerization method. The obtained samples were exemplified by Fourier transform-infrared spectroscopy (FT-IR) and thermogravimetric-differential thermal analysis-differential thermogravimetry (TG-DTA-DTG). Electrochemical capacitance (Cs, F/g) of electrodes fabricated from PPy and HPyCs over stainless steel in the presence of sulphonated polysulphone as binder has been investigated in $\mathrm{KOH}$ solution (1.0 M) with reference to $\mathrm{Ag} / \mathrm{AgCl}$ at scan rate (V/s) ranging 0.001-0.2. HPyC3\% has shown Cs of 445.75F/g along with energy and power densities of 14. $37 \mathrm{Wh} / \mathrm{kg}$ and $596.54 \mathrm{Wh} / \mathrm{kg}$ respectively, which is greater as compared to 200.56F/g for PPy.

Conclusion: The composites show good charge-discharge with improved electrochemical cyclic stability of the HPyCs over PPy. This behaviour points out that fabricated HPyCs may dole out as prospective electrode materials for development of electrochemical supercapacitors.
\end{abstract}

Keywords: Polypyrrole, Haemoglobin, Electrochemical capacitance, Sulphonated polysulphone

\section{Background}

The scarceness of power owing to emergent masses, undue worldwide upgrading and energy expenditure in domestic and industrialized areas may elevate the demand for energy storage devices (Ramachandran et al. 2015; Wang et al. 2012). Therefore, the improved energy-sustainable and energy-efficient economy depends on the ability to produce novel materials for electrochemical supercapacitor (Ghosh et al. 2016). In modern period, the polymer composites (PCs) have engrossed considerable interest globally due to their scientific and technical use in electrochemical power supply such as automotives, fuel cells, handy electronics, batteries and supercapacitors (Hanemann and Szabó 2010). For preeminent viable preservation and storage of electrochemical energy, there has been

\footnotetext{
* Correspondence: komal.chem89@gmail.com

Department of Chemistry, G. B. Pant University of Agriculture and Technology, Pantnagar, Uttarakhand 263 145, India
}

rising requirement of $\mathrm{PCs}$ derived through doping of metal ions into conducting polymer-bearing enhanced electrical conductivity (Mane et al. 2014), dielectric (Guo et al. 2013), thermoelectric properties (Du et al. 2012), sensory (Maity and Chatterjee 2015) and supercapacitors application (Ghosh et al. 2016). The condensed over-potential along with high rates of charge-discharge and extended cyclic stability are the primary aspects of such prepared PCs (Ramachandran et al. 2015).

Intrinsically conducting polymers with conjugated double bonds have attracted much consideration as advanced materials (Wang et al. 2001). Among these, PPy has been regarded as predictive material expansively studied with respect to its commercial appliances due to its high surface area, low cost, ease of polymerization and good stability that can be regulated by doping (Deng et al. 2014; Qian et al. 2013; Snook et al. 2011). In earlier studies, PPy doped 2,2'-bipyridine (Thakur and Lokhande 2018a), $\mathrm{Cu}(\mathrm{OH})_{2}$ (Thakur and 
Lokhande 2017a), $\mathrm{MnO}_{2}$ (Li et al. 2010), $\mathrm{CeO}_{2}$ (Wang et al. 2016), $\mathrm{TiO}_{2}$ (Gao et al. 2014), $\mathrm{RuO}_{2}$ (Zang et al. 2008), Fe (Cysewska et al. 2015), $\mathrm{Fe}_{2} \mathrm{O}_{3}$ (Navale et al. 2014), Porphyrin (Zhou et al. 2007) and Hb (Baghayeri et al. 2015). Recently, work reported on $\mathrm{V}_{2} \mathrm{O}_{5}$ (Ingole and Lokhande 2016), $\mathrm{FeO}(\mathrm{OH})$ (Thakur and Lokhande 2018b and $\mathrm{Fe}_{3} \mathrm{O}_{4}$ (Thakur and Lokhande 2017b) as electrode materials deposited on stainless steel for the improvement of supercapacitance and battery applications. In this perspective, macrocyclic metal ion $\mathrm{Hb}$ functionalized PPy has been investigated as electrode materials in the development of high power energy storage systems.

$\mathrm{Hb}$ electron transfer reaction is an attractive topic because of its wide applications in biosensors, bioelectronics and energy storage systems. It is an imperative redox respiratory protein in red cells and composed of four polypeptide chains, each has one iron heme group (Scheller et al. 2005). Due to its commercial ease of utilization, known structure, judicious cost, high stability and capability rate, $\mathrm{Hb}$ is considered as an ideal model for the study of electrochemical performance for supercapacitor (Khairy and El-Safty 2014).

The present study has put emphasis on the simplified approach towards preparation of novel HPyCs through CTAB-assisted polymerization of $\mathrm{Py}$ in the presence of different concentrations of $\mathrm{Hb}(\%, w / w)$ ranging $1-3$ at $30 \pm 1{ }^{\circ} \mathrm{C}$ in aqueous medium. The process of polymerization was initiated with $\mathrm{FeCl}_{3}$ that serves as oxidant (Mudila et al. 2013). Fabrication of HPyCs, its characterization through spectral FT-IR and TGA-DTA-DTG suggest the interaction of $\mathrm{Hb}$ moiety in PPy matrix and thermally stable behaviour of composites. The synthesized HPyCs have shown their significance as a high power electrode material with $\sim 1.5 \%$ electro-capacitive decrease during the first 1000 cycles at scan rate of $0.1 \mathrm{~V} / \mathrm{s}$. To the best of our information, we exhibit foremost, the electrochemical supercapacitance behaviour of the proposed HPyCs. New and interesting results were observed with increasing concentration of $\mathrm{Hb}$ in the matrix of PPy, suggesting its importance as a potential entrant for upcoming generation for energy strategies.

\section{Methods}

\section{Chemicals and reagents}

Commercially available haemoglobin (Otto Kemi, India), pyrrole (>99\% Across Chemicals), polysulphone (Mw; $\left.16 \times 10^{3}\right)$, CTAB (>99\% sd. Fine Chemical India), graphite (>98.0\%, $500 \mu \mathrm{m}$ Loba Cheme India), and chlorosulphonic acid (> 99\% Sigma Aldrich). Other chemicals and solvents were obtained from S.D. Fine Chemicals India.

\section{Preparation of SPS}

SPS applied as binder and one of the constituent in the matrix was synthesized through sulphonation of polysulphone resin (PSO) with chlorosulphonic acid in dichloromethane as illustrated (Unnikrishnan et al. 2012). The precipitated SPS was filtered off and repeatedly washed with aqueous solution of sodium hydroxide $(10 \%, w / v)$ for the exclusion of unreacted chlorosulphonic acid. Ultimately, the polymer was washed with distilled water to eradicate traces of solvent until neutral water was obtained and dried at 80 $\pm 1{ }^{\circ} \mathrm{C}$ overnight.

\section{Synthesis of HPyCs}

All the HPyCs were synthesized by CTAB-assisted dilute polymerization in a thermostatically controlled glass reactor equipped with mechanical stirrer, thermometer and a dropping funnel. The suspension of Py in de-ionized water $(0.12 \mathrm{~mol} / \mathrm{dL})$ stabilized with CTAB $\left(1.15 \mathrm{~g}, 3.50 \times 10^{-3} \mathrm{~mol}\right)$ was placed in the reactor. To this, the necessitate concentration of $\mathrm{Hb}$ $(1-3 \%, w / w)$ was added and contents were stirred @ $500 \mathrm{rpm}$ over $15 \mathrm{~min}$ at $30 \pm 1{ }^{\circ} \mathrm{C}$. Meanwhile, the aqueous solution of $\mathrm{FeCl}_{3}\left(30 \mathrm{~mL}, 1.85 \times 10^{-2} \mathrm{~mol} /\right.$ $\mathrm{dL}$ ) in deionized water was added drop wise to the suspension of Py. The polymerization process was allowed to progress @ $500 \mathrm{rpm}$ over $24 \mathrm{~h}$ at $30 \pm 1^{\circ}$ C. The formation of HPyCs was determined through appearance of black colour precipitate. HPyCs with $\geq$ 95\% yield were separated through filtration from the reaction mixture and washed with distilled water until pale filtrate was achieved. The obtained HPyCs were dried at $60 \pm 1{ }^{\circ} \mathrm{C} / 400 \mathrm{mmHg}$ over $8 \mathrm{~h}$. Following the aforementioned method, HPyCs were synthesized with doping $(\%, w / w) 1-3$ of $\mathrm{Hb}$ respectively. PPy was also synthesized in $85 \%$ yield under identical conditions (Mudila et al. 2013).

\section{Fabrication of working electrodes}

Prior to deposition, commercially available 316-SS with $1 \mathrm{~cm}^{2}$ area (mesh size 320,600) and $0.16 \mathrm{~mm}$ thickness was well polished with emery paper followed by cleaning the surface with acetone. Stainless steel(SS) were fabricated through coating a composition of electroactive material $(70 \mathrm{mg})$ along with graphite $(10 \mathrm{mg})$ which was added to a solution of an effective binder SPS (5 g/dL) in $N$-methyl Pyrollidone. The contents were ultrasonicated for $15 \mathrm{~min}$. The mass loading slurry $(100 \mu \mathrm{l})$ was condensed on a SS substrate which acts as a current collector. The treated substrate was desiccated at room temperature for $4 \mathrm{~h}$ followed by drying at $60{ }^{\circ} \mathrm{C} / 400 \mathrm{mmHg}$ for $48 \mathrm{~h}$. This has afforded working electrodes with mass thickness of electroactive materials by $0.05 \pm 0.01 \mathrm{mg}$ 
over SS substrate. The electrodes were analyzed after $24 \mathrm{~h}$ of fabrication (Mudila et al. 2013).

\section{Characterizations}

Fourier transform-infrared (FT-IR) spectra were recorded over Thermo Nicolet in KBr. Simultaneous thermogravimetric-differential thermal analysis-differ ential thermogravimetry (TG-DTA-DTG) data were documented over EXSTAR TG/DTA 6300 at sample size $(\mathrm{mg})$ ranging $8-11.2 @ 10^{\circ} \mathrm{C} / \mathrm{min}$ in air.

The electrochemical measurements were recorded over IVIUM Potentiostat-Galvanostat Netherlands BV at current compliance $1 \mathrm{~mA}$, voltage ranging -0.1 to $-0.6 \mathrm{~V}$ at scan rate $(\mathrm{V} / \mathrm{s})$ of $0.001-0.2$. The electrochemical properties, capacitive behaviour and stability of electrodes were studied by Cyclic Voltammetry $(\mathrm{CV})$ and Electron Impedance Spectroscopy (EIS). All the electrochemical performance were analysed in a three electrode cell assembly equipped with reference to $\mathrm{Ag} / \mathrm{AgCl}, \mathrm{Pt}$ foil $(1 \mathrm{~cm} 2$ area) as counter electrodes and working electrode in $\mathrm{KOH}$ solution $(1.0 \mathrm{M})$. Cs of materials was calculated from the voltammetric charges by the CV curve, according to relation:

$$
\mathrm{Cs}=\mathrm{qa}+|\mathrm{qc}| / 2 m \Delta \mathrm{V}
$$

where qa and qc are the voltammetric charges on anodic and cathodic scans in the capacitive potential region $(\Delta \mathrm{V})$ and $m$ being the mass of electroactive material.

\section{Results and discussion}

\section{FT-IR spectra}

Figure 1 reveals FT-IR spectra of PPy, $\mathrm{Hb}$ and respective $\mathrm{HPyC} 3 \%$. It may be deduced that most of the

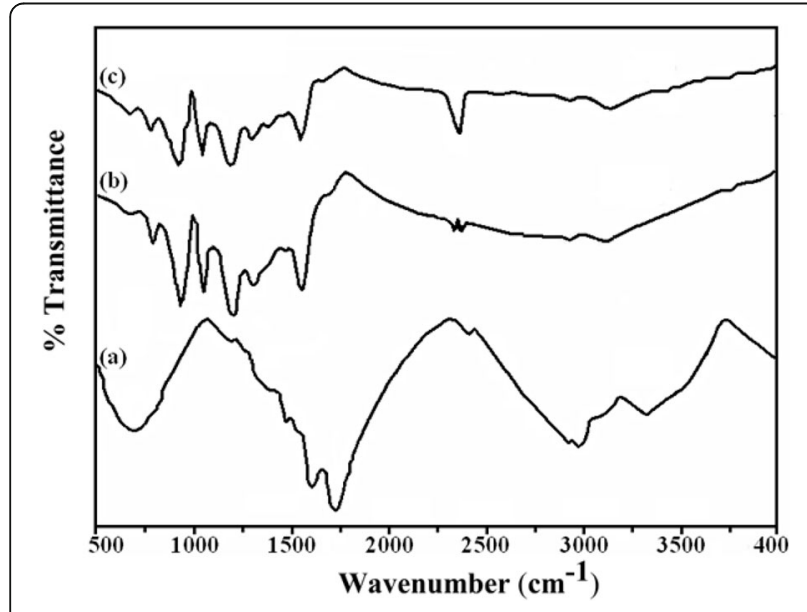

Fig. 1 FT-IR spectra of (a) Hb, (b) PPy and (c) HPyC3\% assignments of PPy are maintained in the HPyC3\% spectra from 500 to $1750 \mathrm{~cm}^{-1}$. Hb shows characteristic absorptions at $v \mathrm{O}-\mathrm{H}\left(3289 \mathrm{~cm}^{-1}\right)$ which departed in the spectra of $\mathrm{HPyC} 3 \%$, thus verifying the interaction of secondary amino group of PPy with carboxylic group of $\mathrm{Hb}$ moiety. The other characteristic absorption of $\mathrm{Hb}$ are $\nu \mathrm{C}=\mathrm{O}\left(1652.00 \mathrm{~cm}^{-1}\right), \nu \mathrm{C}-\mathrm{N}\left(1541 \mathrm{~cm}^{-1}\right), \nu \mathrm{C}-\mathrm{O}$ $\left(612 \mathrm{~cm}^{-1}\right.$ ) (Aboul-Enein et al. 2014; Kong and $\mathrm{Yu}$ 2007), and $\nu \mathrm{C}-\mathrm{H}\left(2927 \mathrm{~cm}^{-1}\right)$. PPy shows characteristic FT-IR absorptions resultant to $v \mathrm{~N}-\mathrm{H}\left(3450.10 \mathrm{~cm}^{-1}\right)$ (Jiwei et al. 2008), $v \mathrm{C}-\mathrm{H}\left(2925.10 \mathrm{~cm}^{-1}\right)$ (Sonavane et al. 2010), symmetrical $v C=C\left(1652.10 \mathrm{~cm}^{-1}\right), \nu C-C$ $\left(1463.20 \mathrm{~cm}^{-1}\right)$ and $v \mathrm{C}-\mathrm{N}\left(1513.20 \mathrm{~cm}^{-1}\right)$ (Sonavane et al. 2010). These absorption peaks correspond to the formation of 2, 5-substituted PPy (Qiao et al. 2010; Ramachandran et al. 2015), $v \mathrm{C}-\mathrm{H}\left(1397 \mathrm{~cm}^{-1}\right)$ in-plane bending $(\mathrm{Qu}$ et al. 2010) and $v \mathrm{C}-\mathrm{H}$ out of plane bend $\left(932 \mathrm{~cm}^{-1}\right.$ ) (Ramachandran et al. 2015). Doping induced bands associated with conjugated backbone for PPy appeared at $1160.40 \mathrm{~cm}^{-1}$ (Liu et al. 2005; Yang et al. 2011). HPyC3\% shows characteristic absorption peak at $\nu \mathrm{N}-\mathrm{H} \quad\left(3402 \mathrm{~cm}^{-1}\right), \quad \nu \mathrm{C}-\mathrm{H} \quad\left(2917 \mathrm{~cm}^{-1}\right), \nu \mathrm{C}=\mathrm{O}$ $\left(1655 \mathrm{~cm}^{-1}\right)$ and $\nu \mathrm{C}-\mathrm{N}\left(1528 \mathrm{~cm}^{-1}\right)$ are nearly similar to that of $\mathrm{Hb}$. For further qualitative phase interaction of $\mathrm{Hb}$ into PPy matrix was investigated through Scanning Electron Microscope (SEM) micrograph mentioned in Additional file 1.

\section{Thermal characteristics}

The TGA curve of PPy, $\mathrm{Hb}$ and $\mathrm{PPy} / \mathrm{Hb}$ with $3 \% \mathrm{Hb}$ is shown in Fig. 2a. In the case of PPy, the weight loss was observed in two stages at $200{ }^{\circ} \mathrm{C}(13.04 \%)$ and at $300{ }^{\circ} \mathrm{C}(100 \%)$; the first one was due to physisorbed water molecule and volatile impurities while the second one was due to the degradation of unsaturated group in polymer (Jakab et al. 2007; Basavaraja et al. 2009). In the case of $\mathrm{Hb}$, first weight loss was observed at $190{ }^{\circ} \mathrm{C}(9.1 \%)$, second weight loss was observed at $339{ }^{\circ} \mathrm{C}(42.6 \%)$ and third weight loss was found at $504{ }^{\circ} \mathrm{C}(50.7 \%)$. In $\mathrm{PPy} / \mathrm{Hb}$ composite, the first weight loss at $200{ }^{\circ} \mathrm{C}(11.73 \%)$ is due to removal of oligomer molecules and second weight loss up to $590{ }^{\circ} \mathrm{C}(27.75 \%)$ is because of degradation of PPy. The minimum loss of $\mathrm{Hb}$ from $\mathrm{PPy} / \mathrm{Hb}$ is responsible for higher thermal stability of the composite material. Figure $2 \mathrm{~b}$ shows the DTA curve of pure PPy, $\mathrm{Hb}$ and $\mathrm{PPy} / \mathrm{Hb}$. Due to polymeric degradation of material, a broad exothermic peak ranging from 264 to $582{ }^{\circ} \mathrm{C}$ and 268 to $597{ }^{\circ} \mathrm{C}$ was observed in PPy and $\mathrm{PPy} / \mathrm{Hb}$ respectively. Shifting of the exothermic peak in PPy/ $\mathrm{Hb}$ assures the results of TGA indicating higher thermal stability of $\mathrm{PPy} / \mathrm{Hb}$. The comparative DTG analysis of $\mathrm{PPy}, \mathrm{Hb}$ and $\mathrm{PPy} / \mathrm{Hb}$ composite as derivatized weight loss vs. temperature is shown in Fig. 2c. 

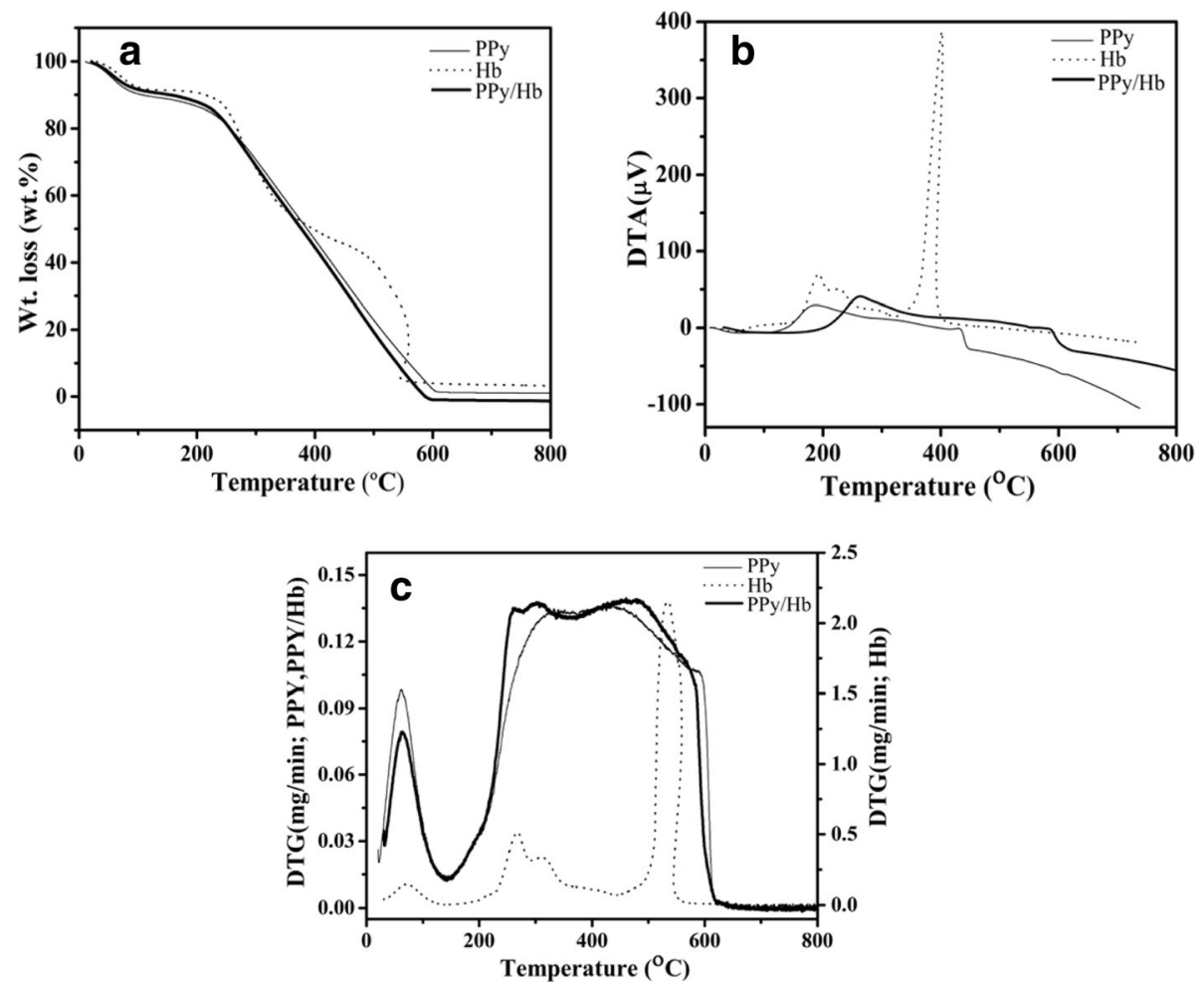

Fig. 2 a TGA. b DTA. c DTG

Weight loss of PPy decomposition was observed at $65{ }^{\circ} \mathrm{C}$ and $260{ }^{\circ} \mathrm{C}$ to $575{ }^{\circ} \mathrm{C}$ with $79 \mu \mathrm{g} / \mathrm{min}$ and 135 to $107 \mu \mathrm{g} / \mathrm{min}$ weight losses respectively whereas in case of $\mathrm{Hb}$ decomposition weight loss was found with 0.51 to $0.33 \mathrm{mg} / \mathrm{min}$ at 267 to $316{ }^{\circ} \mathrm{C}$ and $2.13 \mathrm{mg} /$ $\min$ at $530{ }^{\circ} \mathrm{C}$ respectively. However, in the case of $\mathrm{PPy} / \mathrm{Hb}$, the decomposition was found $92 \mu \mathrm{g} / \mathrm{min}$ at $62{ }^{\circ} \mathrm{C}$ and 128 to $106 \mu \mathrm{g} / \mathrm{min}$ from 301 to $590{ }^{\circ} \mathrm{C}$ respectively. Thus, it could be inferred from DTG studies that rate of thermal decomposition was lower in the case of $\mathrm{PPy} / \mathrm{Hb}$, whereas higher in the case of
PPy. The higher thermal resistance of $\mathrm{PPy} / \mathrm{Hb}$ was due to incorporation of $\mathrm{Hb}$ in the PPy matrix.

\section{Electrochemical analysis}

Electrochemical studies on $\mathrm{Hb}$, PPy and respective HPyCs electrodes with $(\%, w / w)$ ranging $1-3$ deliver us exciting conclusions which demonstrate HPyCs as quite proficient material for preparation and its development as a material for energy storage devices. All the materials signify voltammogram in the voltage range of -0.6 to $-0.1 \mathrm{~V}$ at different scan rates $(\mathrm{V} / \mathrm{s})$ of $0.001-0.2$ in
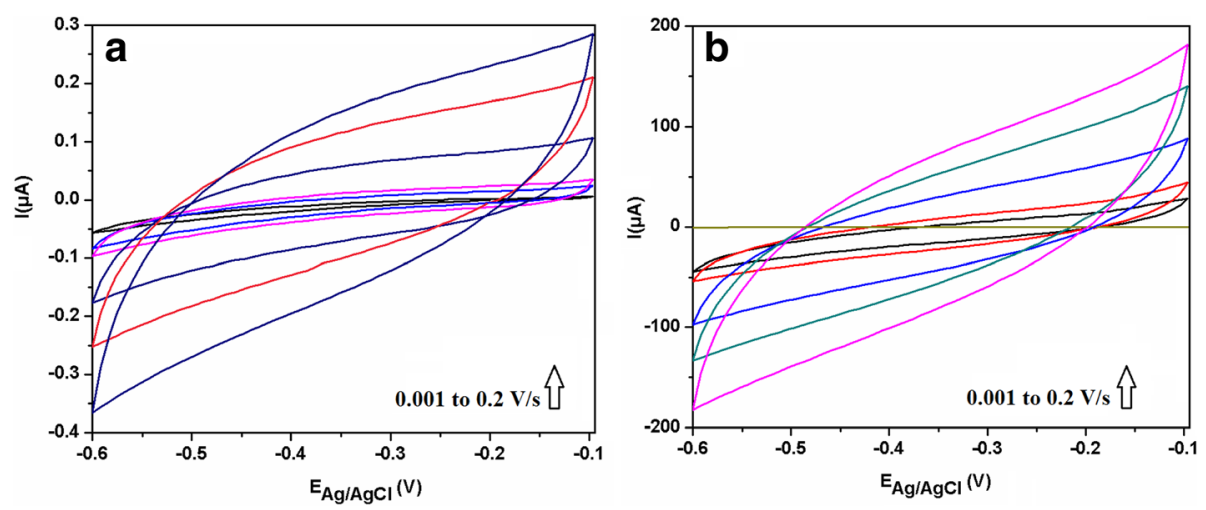

Fig. $3 \mathrm{CV}$ of $\mathbf{a} \mathrm{Hb}$ and $\mathbf{b}$ PPy at various scan rates 

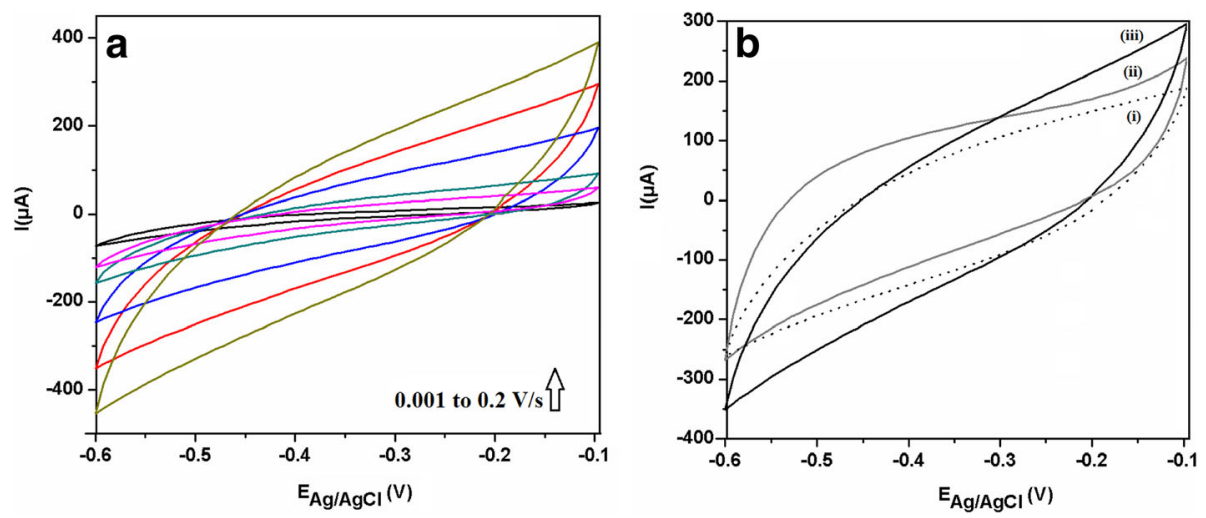

Fig. $4 \mathrm{CV}$ of a HPyC3\% at all scan rates. b CV of HPyCs 1-3\% (i-iii) at $0.01 \mathrm{~V} / \mathrm{s}$

1.0 $\mathrm{M} \mathrm{KOH}$ close to a rectangular shape with no current peak, which indicates a distinctive capacitive behaviour with fine charge propagation (Ghosh et al. 2016; Ramya et al. 2013). Hb has been predictable to involve flourishing ability and a prospective material to accumulate energy (Khairy and El-Safty 2014). The CV was taken in the above held potential range to provide specific capacitance of 3.20 to $0.20 \mathrm{~F} / \mathrm{g}$ (Fig. 3b). With scan rates, a regular increase in the peak currents has been observed for PPy electrodes and the Cs ranges from 200.56 to $14.80 \mathrm{~F} / \mathrm{g}$ in Fig. 3a. Figure 4a exhibits the intensification in specific capacitance for $\mathrm{HPyC} \%$ which has been ranged from 445.75 to $20.60 \mathrm{~F} / \mathrm{g}$. With increasing portion of $\mathrm{Hb}(1-3 \% w / w)$ in the matrix of polymer, a steady increase was observed in the specific capacitance of HPyCs at $0.01 \mathrm{~V} / \mathrm{s}$ (Fig. 4b). Figure 5a illustrates the comparative specific capacitance of $\mathrm{Hb}$, PPy and $\mathrm{HPyC} 3 \%$ at scan rate of $0.01 \mathrm{~V} / \mathrm{s}$ which demonstrate $\mathrm{HPyC} 3 \%$ to be most supercapacitive which is further confirmed with the comparative histogram of $\mathrm{Cs}$ of all the materials (Fig. 5b). The increase in the capacitance of HPyCs may be attributed to the formation of synergistic effect among secondary amine group of PPy with carboxylic group of $\mathrm{Hb}$ moiety, which augment the surface active sites of the HPyCs. Such HPyCs consequently amplify the active material usage as of speedy electron transfer in addition to the storage accumulation for ions. On the contrary, the decrease of capacitance with increasing scan rate in CV curves can be elucidate to the fact that, at elevated scan rate, charge dispersion is not able to pursue the variant in electric field and thus proceeds small capacitance or energy density and high power density.

The energy density (E) and power density (P) for PPy and $\mathrm{HPyC} \%$ were estimated respectively through following equations:

$$
\begin{aligned}
& E=\frac{C s(\Delta V)^{2}}{2} \\
& P=\frac{E}{\Delta t} x 3600
\end{aligned}
$$
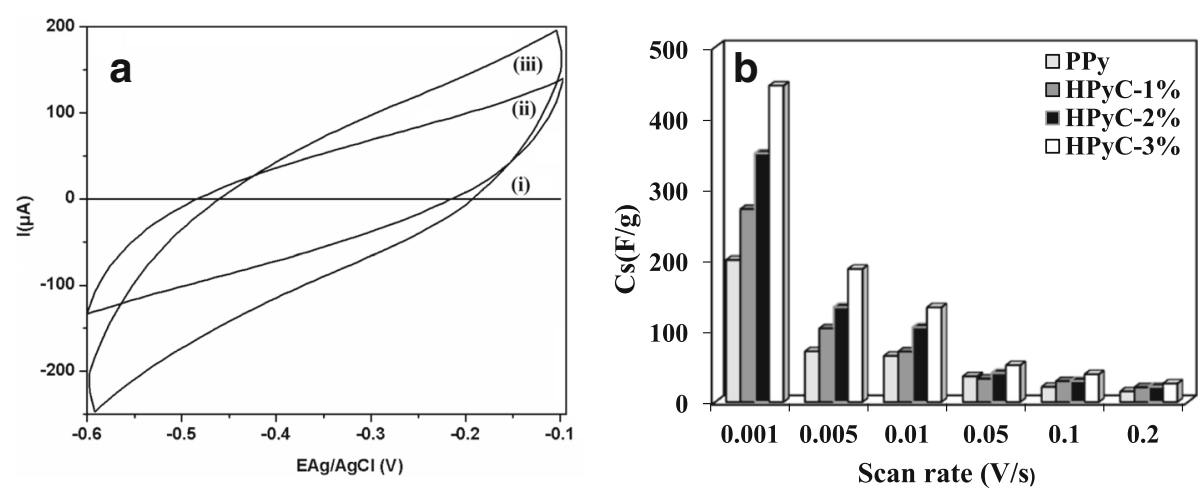

Fig. 5 a CV of Hb, PPy and HPyC3\% (i-iii) at $0.01 \mathrm{~V} / \mathrm{s}$. b Specific capacitance of all materials 

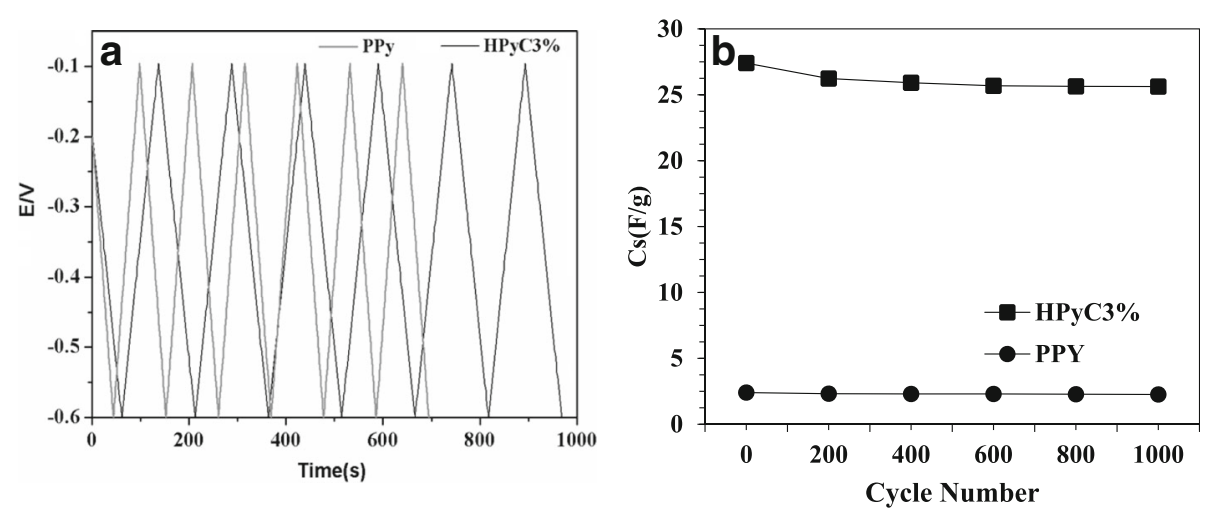

Fig. $\mathbf{6}$ a Charge-discharge curves. $\mathbf{b}$ Effect of number of cycle on the Cs and stability

where "Cs" is specific capacitance, $\Delta \mathrm{V}$ is the applied initial voltage and " $\Delta \mathrm{t}$ " is the corresponding discharge time in hour (Fu et al. 2018; Mudila et al. 2017). The maximum energy density of $6.26 \mathrm{Wh} / \mathrm{kg}$ and $14.37 \mathrm{Wh} / \mathrm{kg}$ was encountered for PPy and $\mathrm{HPyC} \%$, while the corresponding power density of $259.76 \mathrm{~W} /$ $\mathrm{kg}$ and $596.54 \mathrm{~W} / \mathrm{kg}$ was reported respectively.

Figure 6a shows charging-discharging curves of PPy and $\mathrm{HPyC} 3 \%$ recorded in the voltage range from -0.6 to $-0.1 \mathrm{~V}$ at an applied current density of $10 \mathrm{~mA} / \mathrm{cm}^{2}$. The charge/discharge curves exhibit reversible characteristics devoid of noticeable deviation in each cycle; these charge/discharge curves are almost linear in the total range of potential with constant slopes, signifying perfect electro-capacitive behaviour. This suggests good electrochemical stability for the HPyCs electrodes with a capacitive decrease of $1.5 \%$ during the first 1000 cycles at a scan rate of $0.1 \mathrm{~V} / \mathrm{s}$ that indicates improved cyclic stability of the HPyCs over PPy (Fig. 6b), making them

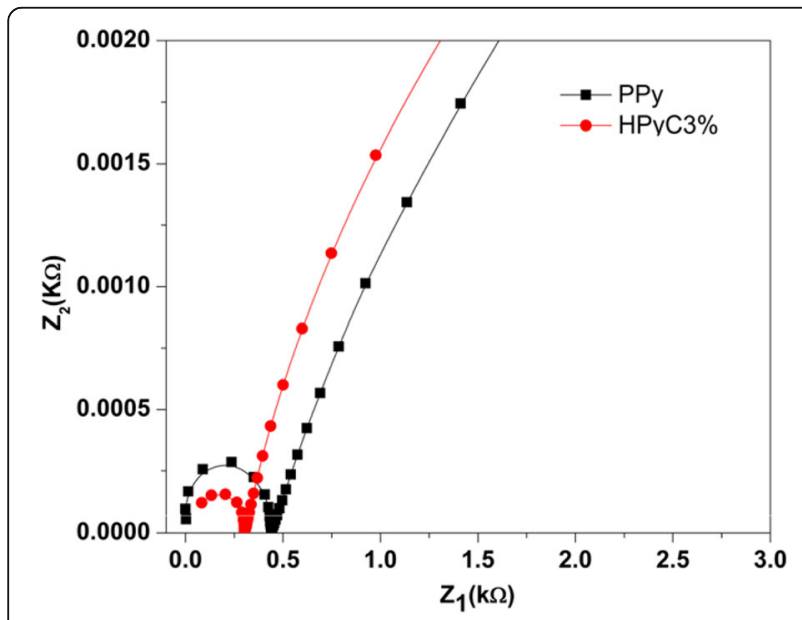

Fig. 7 Nyquist plots of PPy and $\mathrm{HPyC} \%$ appropriate for improvement of electrochemical supercapacitors (Table 1). Electrochemical Impedance Spectroscopy (EIS) was performed to determine the parameters for electron transfer reactions at the interface of the working electrode. EIS spectra of PPy and $\mathrm{HPyC} 3 \%$ are measured in the frequency ranges from 0.1 to $1000 \mathrm{~Hz}$ with pulse amplitude of $0.03 \mathrm{mV}$. Nyquist diagram for the PPy and HPyC3\% electrodes are shown in Fig. 7. The Nyquist diagram of both the electrodes consist of the two parts, one is quasi semicircle in the high frequency region and another shows linear part at low frequency region. The electrolyte resistance (Rs), can be found from the semicircle interception point on the real axis while the charge transfer resistance (Rct), was calculated by measuring the magnitude of the diameter of semicircle on the electrode surface. PPy illustrate high impedance values compared with those obtained for the $\mathrm{HPyC} \%$. The curves achieved for the $\mathrm{HPyC} \%$ also showed a deviation in slope from a vertical position in relation to PPy, which is attributed to the low Rct values and may be ascribed to the high porosity and mobility inside the electrodes. This supports electronic transfer in the HPyCs, thus significantly reducing the $R$ ct value, making it more capacitive. The increase in electron transfer in HPyC3\% is perhaps attributable to the charge transfer between $\mathrm{Hb}$ and PPy. This can be partly proven by the FT-IR spectrum, which suggests interaction of electrons

Table 1 Performance comparison of Hb-based PPy supercapacitors. The table shows the comparison of electrochemical performance of reported PPy and HPyCs in this work

\begin{tabular}{lllllll}
\hline S.No. & $\begin{array}{l}\text { Name of } \\
\text { materials }\end{array}$ & Electrolyte & $\mathrm{Cs}(\mathrm{F} / \mathrm{g})$ & $\begin{array}{l}\text { Current } \\
\text { density } \\
\left(\mathrm{mA} / \mathrm{cm}^{2}\right)\end{array}$ & $\begin{array}{l}\text { Energy } \\
\text { density } \\
(\mathrm{Wh} / \mathrm{Kg})\end{array}$ & $\begin{array}{l}\text { Power } \\
\text { density } \\
(\mathrm{W} / \mathrm{Kg})\end{array}$ \\
\hline 1 & PPy & $1.0 \mathrm{M} \mathrm{KOH}$ & 200.56 & 10 & 6.26 & 259.76 \\
2 & HPyC3\% & $1.0 \mathrm{M} \mathrm{KOH}$ & 445.75 & 10 & 14.37 & 596.54 \\
\hline
\end{tabular}


among $\mathrm{Hb}$ and PPy. Also, due to the large surface area of $\mathrm{Hb}$, may serve as linking PPy and results in higher conductivity, thus lowering the Rct values obtained for $\mathrm{HPyC} \%$. The Rs and Rct for HPyC3\% is less than the PPy, which conclude that HPyCs is highly conductive as well as fairly stable as an electrode material.

\section{Conclusions}

A series of haemoglobin/polypyrrole composites (HPyCs) were prepared through $\mathrm{FeCl}_{3}$-assisted dilute polymerization of Py. The FT-IR reveals the physical interface between the two and TG-DTA-DTG informs the thermal assets of HPyCs which get more stable with percentage of $\mathrm{Hb}$. CV studies suggest that these HPyCs having varying concentration of $\mathrm{Hb}(1-3 \%)$ in their matrix can be employed as potential material for the above said property. $\mathrm{HPyC} 3 \%$ had provided with specific capacitance of $445.75 \mathrm{~F} / \mathrm{g}$ which is higher compared to PPy that comprises of capacitance of $200.56 \mathrm{~F} / \mathrm{g}$. The consecutive scans of HPyC3\% electrode for 1000 cycles at the scan rate of $0.1 \mathrm{~V} / \mathrm{s}$ in $\mathrm{KOH}(1.0 \mathrm{M})$ with capacitive retention of $\sim 98.5 \%$ illuminating good cyclic stability of electrode material. The charge-discharge curves are nearly linear in the total range of potential with constant slopes, presenting idyllic electro-capacitive behaviour. The maximum energy density of $6.26 \mathrm{Wh} / \mathrm{kg}$ and $14.37 \mathrm{Wh} / \mathrm{kg}$ was encountered for PPy and HPyC3\%, while corresponding power density of $259.76 \mathrm{~W} / \mathrm{kg}$ and $596.54 \mathrm{~W} / \mathrm{kg}$ was reported respectively. The HPyCs showed the lowest impedance values and charge-transfer resistance compared to the PPy, indicating that electron transfer in the HPyCs was favoured by an association between the constituent materials. The present effort demonstrates a simple and cost-effective approach for synthesis of the electrochemically commercial HPyCs with improved capacitance. This gives an idea about the preparation of the electrode materials for the development of electrochemical energy storage devices.

\section{Additional file}

Additional file 1: SEM micrograph of PPy and HPyCs (DOCX 628 kb)

\section{Abbreviations}

CTAB: Cetyltrimethylammonium bromide; Hb: Haemoglobin; PCs: Polymer Composites; PPy: Polypyrrole; PSO: Polysulphone; SPS: Sulphonated polysulphone; SS: Stainless steel

\section{Acknowledgements}

The author would like to thank CSIR, India, for awarding JRF and SRF.

\section{Funding}

Not applicable

Availability of data and materials

Not applicable

\section{Authors' contributions}

KK and MGHZ conceived the plan. KK and IJ performed the experiments, fabrication of electrode and other electrochemical studies. KK, IJ and MGHZ performed the data analysis. KK, IJ and MGHZ did the manuscript writing and execute the data interpretation. All authors had read and agreed for the final manuscript.

\section{Competing interests}

The authors declare that they have no competing interests.

\section{Publisher's Note}

Springer Nature remains neutral with regard to jurisdictional claims in published maps and institutional affiliations.

Received: 1 August 2018 Accepted: 10 October 2018

Published online: 27 October 2018

\section{References}

Aboul-Enein Y, Bunaciu AA, Fleschin S. Evaluation of the protein secondary structures using Fourier transform infrared spectroscopy. GUJS. 2014;27(1):637-44.

Baghayeri M, Zare EN, Lakouraj MM. Monitoring of hydrogen peroxide using a glassy carbon electrode modified with hemoglobin and a polypyrrole-based nanocomposite. Microchem Acta. 2015;182(3-4):771-9.

Basavaraja C, Kim NR, Jo E, Pierson R, Huh DS, Venkataraman A. Transport properties of polypyrrole films doped with sulphonic acids. Bull Kor Chem Soc. 2009;30(11):2701-6.

Cysewska K, Virtanen S, Jasi Å SP. Electrochemica activity and electrical properties of optimized polypyrrole coatings on iron. J Electrochem Soc. 2015;162(12):307-13.

Deng $H$, Lin L, Ji M, Zhang S, Yang M, Fu Q. Progress on the morphological control of conductive network in conductive polymer composites and the use as electroactive multifunctional materials. Prog Polym Sci. 2014;39(4):627-55.

Du Y, Shen SZ, Cai K, Casey PS. Research progress on polymer-inorganic thermoelectric nanocomposite materials. Prog Polym Sci. 2012;37(6):820-41.

Fu C, Ma Q, Liu H, Tang W. Effects of graphene oxide on the conductivity and capacitance of Polypyrrole. Int J Electrochem Sci. 2018;13:4267-75.

Gao Y, Wang Y, Xu X, Ding K, Yu D. Synthesis of polypyrrole-titanium dioxide brush-like nanocomposites with enhanced supercapacitive performance. RSC Adv. 2014;4(109):63719-24.

Ghosh S, Maiyalagan T, Basu RN. Nanostructured conducting polymers for energy applications: towards a sustainable platform. NLM. 2016;8(13):6921-47.

Guo J, Gu H, Wei H, Zhang Q, Haldolaarachchige N, Li Y, Young DP, Wei S, Guo Z. Magnetite-polypyrrole metacomposites: dielectric properties and magnetoresistance behavior. J Phys Chem C. 2013;117(19):10191-202.

Hanemann T, Szabó DV. Polymer-nanoparticle composites: from synthesis to modern applications. Mater. 2010;3(6):3468-517.

Ingole RS, Lokhande BJ. Effect of pyrolysis temperature on structural, morphological and electrochemical properties of vanadium oxide thin films. J Anal Appl Pyrolysis. 2016;120:434-40.

Jakab E, Mészáros E, Omastová M. Thermal decomposition of polypyrroles. J ThermAnal Cal. 2007;88(2):515-21.

Jiwei L, Jingxia Q, Miao Y, Chen J. Preparation and characterization of Ptpolypyrrole nanocomposite for electrochemical reduction of oxygen. J Mater Sci. 2008:43(18):6285.

Khairy M, El-Safty SA. Hemoproteins-nickel foam hybrids as effective supercapacitors. Chem Commun. 2014;50(11):1356-8.

Kong J, Yu S. Fourier transform infrared spectroscopic analysis of protein secondary structures. Acta Biochim Biophys Sinica. 2007;39(8):549-59.

Li J, Cui L, Zhang X. Preparation and electrochemistry of one-dimensional nanostructured $\mathrm{MnO}_{2}$ /PPy composite for electrochemical capacitor. Appl Surf Sci. 2010;256(13):4339-43.

Liu L, Zhao C, Zhao Y, Jia N, Zhou Q, Yan M, Jiang Z. Characteristics of polypyrrole (PPy) nano-tubules made by templated ac electropolymerization. Eur Polym J. 2005;41(9):2117-21

Maity S, Chatterjee A. Textile/polypyrrole composites for sensory applications. J Compos. 2015:2356-7252.

Wang LX, Li XG, Yang YL. Preparation, properties and applications of polypyrroles. React Funct Polym. 2001:47(2):125-39.

Mane AT, Navale ST, Pawar RC, Lee CS, Patil VB. Microstructural, optical and electrical transport properties of $\mathrm{WO}_{3}$ nanoparticles coated polypyrrole hybrid nanocomposites. Synth Met. 2014;199:187-95. 
Mudila $\mathrm{H}$, Rana $\mathrm{S}$, Zaidi $\mathrm{MGH}$. Supercritical $\mathrm{CO}_{2}$ aided polyindole-graphene nanocomposites for high power density electrode. Adv Mater Let. 2017:8(3):269-75

Mudila H, Zaidi MGH, Rana S, Joshi V, Alam S. Enhanced electrocapacitive performance of graphene oxide polypyrrole nanocomposites. IJCAS. 2013; 4(3):139-45.

Navale ST, Khuspe GD, Chougule MA, Patil VB. Synthesis and characterization of hybrid nanocomposites of polypyrrole filled with iron oxide nanoparticles. J Phy Chem Solids. 2014;75(2):236-43.

Qian T, Yu C, Wu S, Shen J. A facilely prepared polypyrrole-reduced graphene oxide composite with a crumpled surface for high performance supercapacitor electrodes. J Mater Chem A. 2013;1 (22):6539-42.

Qiao Y-S, L-Z S, Dou T, Hu M. Polymerization and characterization of high conductivity and good adhension polypyrrole films for electromagnetic interference shielding. Chinese J Poly Sci. 2010:28(6):923-30.

Qu B, Xu YT, S-j L, Zheng Y-F, Dai L-Z. Fabrication of Pt nanoparticles decorated PP-MWNTs composites and their electrocatalytic activity for methanol oxidation. Synth Met. 2010;160(7-8):732-42.

Ramachandran R, Chen SM, Kumar GG. An overview of electrochemical energy storage devices of various electrodes and morphological studies of supercapacitors. Int J Electrochem Sci. 2015;10(12):10355-88.

Ramya R, Sivasubramanian R, Sangaranarayanan MV. Conducting polymers-based electrochemical supercapacitors-progress and prospects. Electrochim Acta. 2013:101:109-29.

Scheller FW, Bistolas N, Liu S, Jänchen M, Katterle M, Wollenberger U. Thirty years of haemoglobin electrochemistry. Adv Colloid Interface Sci. 2005. 116(1-3):111-20

Snook GA, Kao P, Best AS. Conducting-polymer-based supercapacitor devices and electrodes. J Power Sources. 2011;196(1):1-12.

Sonavane AC, Inamdar Al, Dalavi DS, Deshmukh HP, Patil PS. Simple and rapid synthesis of NiO/PPy thin films with improved electrochromic performance. Electrochim Acta. 2010;55(7):2344-51.

Thakur AV, Lokhande BJ. $\mathrm{C}_{10} \mathrm{H}_{8} \mathrm{~N}_{2}$-PPy hybrid flexible electrodes: SILAR synthesis and electrochemical study. J Mater Sci- Mater El. 2018a;29(2):1630-5.

Thakur AV, Lokhande BJ. Dip time-dependent SILAR synthesis and electrochemical study of highly flexible PPy-Cu(OH $)_{2}$ hybrid electrodes for supercapacitors. J Solid State Electrochem. 2017a;21(9):2577-84.

Thakur AV, Lokhande BJ. Electrolytic anion affected charge storage mechanisms of $\mathrm{Fe}_{3} \mathrm{O}_{4}$ flexible thin film electrode in $\mathrm{KCl}$ and $\mathrm{KOH}$ : a comparative study by cyclic voltammetry and galvanostatic charge-discharge. J Mater Sci- Mater El 2017b;28(16):11755-61.

Thakur A V, Lokhande B J (2018b) Source molarity affected surface morphological and electrochemical transitions in binder-free $\mathrm{FeO}(\mathrm{OH})$ flexible electrodes and fabrication of symmetric supercapacitive device. Chem Pap 72 (6):1407-1415.

Unnikrishnan L, Madamana P, Mohanty S, Nayak SK. Polysulfone/C30B nanocomposite membranes for fuel cell applications: effect of various sulfonating agents. Polym-Plast Technol. 2012;51(6):568-77.

Wang G, Zhang L, Zhang J. A review of electrode materials for electrochemical supercapacitors. Chem Soc Rev. 2012;41(2):797-828.

Wang X, Wang T, Liu D, Guo J, Liu P. Synthesis and electrochemical performance of $\mathrm{CeO}_{2} /$ PPy nanocomposites: interfacial effect. Ind Eng Chem Res. 2016; 55(4):866-74.

Yang S, Shen C, Liang Y, Tong H, He W, Shi X, Zhang X, H-j G. Graphene nanosheets-polypyrrole hybrid material as a highly active catalyst support for formic acid electro-oxidation. NLM. 2011;3(8):3277-84.

Zang J, Bao SJ, Li CM, Bian H, Cui X, Bao Q, Sun CQ, Guo J, Lian K. Well-aligned cone-shaped nanostructure of polypyrrole/RuO2 and its electrochemical supercapacitor. J Phys Chem C. 2008;112(38):14843-7.

Zhou Q, Li CM, Li J, Cui X, Gervasio D. Template-synthesized cobalt porphyrin/ polypyrrole nanocomposite and its electrocatalysis for oxygen reduction in neutral medium. J Phys Chem C. 2007:111(30):11216-22.

\section{Submit your manuscript to a SpringerOpen ${ }^{\circ}$ journal and benefit from:}

- Convenient online submission

- Rigorous peer review

- Open access: articles freely available online

- High visibility within the field

- Retaining the copyright to your article

Submit your next manuscript at $\boldsymbol{\nabla}$ springeropen.com 